\title{
Die Erfindung der Mobilität
}

Erhard Taverna

\footnotetext{
* L'Aventure Michelin, 32, rue du Clos Four, F-63100 Clermont-Ferrand www.laventuremichelin.com
}

Eine Industriegeschichte als Familiensaga wird selten so gut wie in diesem Aussenquartier von Clermont-Ferrand erzählt.* Nach einer kurzen Fahrt mit der eingleisigen Strassenbahn, die seitlich auf Gummireifen fährt, liegt hinter dem Stade Marcel Michelin das moderne Ausstellungsgebäude.

Einer der weltgrössten Reifenhersteller mit heute 69 Fabriken in 19 Ländern hat in der Hauptstadt der Auvergne seinen Hauptsitz. Die Patrons der Gründerzeit waren auch sozial engagiert. Sie bauten Siedlungen für ihre Arbeiter, Haushaltsschulen, Kinderkrippen und Sportzentren, und sie organisierten die medizinische Betreuung von der Grundversorgung bis zur Rehabilitation. Michelin baute in den 20er Jahren eine vorbildliche Krankenkasse auf, während er gleichzeitig die staatlichen Einrichtungen ablehnte, da er nur dem betriebseigenen System vertraute. Trotz Globalisierung und Wirtschaftskrisen kümmern sich die Unternehmen auch heute noch um gesundheitliche Probleme der Belegschaft. 2011 erhielt die Firmenleitung in Nordamerika zum zweiten Mal die höchste Auszeichnung, die für das soziale und medizinische Management verliehen wird. Bei Michelin ist der Aufbau von Gesundheitszentren mit eigenen Ärzten inbegriffen.

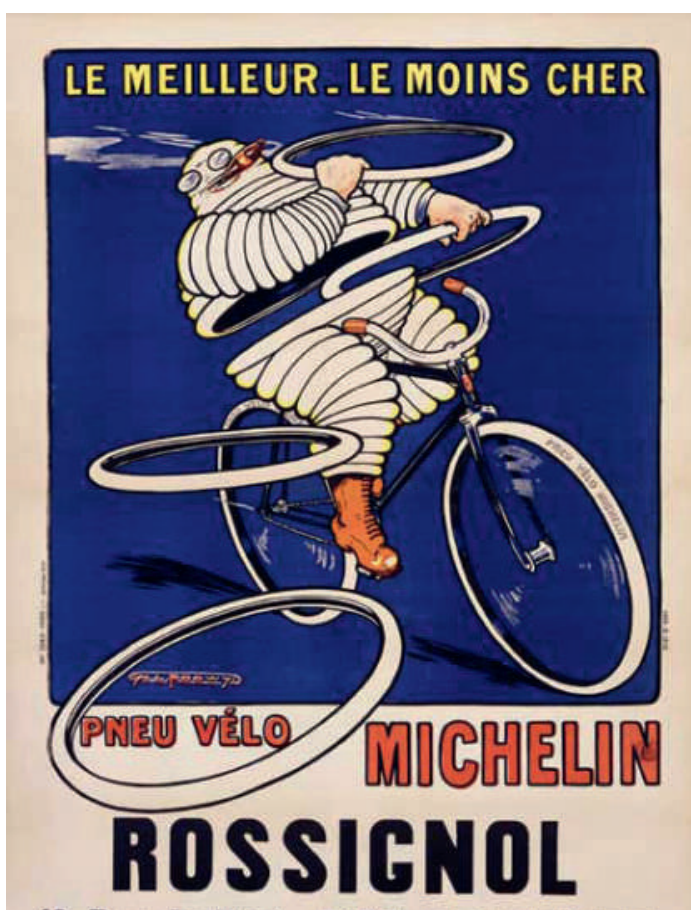

43. Rue du Pont. RIS-ORAmGIS

Auch eine Erfolgsgeschichte: «Bibendum», hierzulande besser bekannt als «Michelin-Männchen», brachte es zu weltweiter Popularität. (c) MICHELIN
Alles begann in den 1830er Jahren, als Frankreich einen industriellen Boom erlebte und die Gründer eine Fabrik für Landmaschinen aufbauten. Der eine Partner heiratete die Nichte des Schotten MacIntosh, der die Lösbarkeit von Kautschuk in Benzin entdeckt hatte und mit wasserdichtem Gewebe ein Vermögen machte. Doch einmal ging die Nachfrage nach Kinderbällen, Gartenschläuchen und Treibriemen zurück, die Firma stand kurz vor der Pleite, als die Enkel Eduard und André Michelin, Ingenieur der eine, Jurist und Maler der andere, 1889 den ersten abnehmbaren Reifen für Fahrräder auf den Markt brachten. Nur ein Jahr zuvor hatte der schottische Tierarzt Dunlop erstmals Reifen aus Gummi konstruiert. Vorher hatte der Reifenwechsel drei Stunden plus eine Nacht zum Trocknen des Leims gebraucht, jetzt dauerte er nur noch 15 Minuten. Die Michelins bewiesen die Überlegenheit ihrer Erfindung, indem sie Nägel auf die Rennstrecken streuen liessen. Nach der Erfindung des Automobils fertigten sie Reifen mit Luftkammern, was vielen Zeitgenossen ein völliger Unsinn zu sein schien. Detailreich und phantasievoll schildern die Ausstellungsmacher den Werdegang einer beispiellosen Erfolgsgeschichte.

Ebenso wichtig wie Erfindungen und Patente war die geniale Werbung beider Brüder über Rad- und Autorennen mit gesponserten Preisen und der Erfindung des berühmten Pneumännchens «Bibendum», auch liebevoll «Bib» genannt, ein bis heute aktuelles und preisgekröntes Logo. Kartografie und Gastronomie wurden mit Strassenkarten, Reiseführern in mehreren Sprachen und den berühmten Michelin-Sternen für heute acht Kategorien dienstbar gemacht. Sie organisierten mobile Werkstätten und den ersten telefonischen Auskunftsdienst. Die ersten Guides von 1906 wurden von Reifenhändlern kostenlos verteilt, sie enthielten Ratschläge für Reifenwechsel und erste Hilfe. 1899 erreichte ein Elektromobil mit Michelinpneus die sagenhafte Geschwindigkeit von $105,882 \mathrm{~km}$ pro Stunde. Bald gab es neue Reifen für die durch den Krieg forcierte Aviatik, wozu die Firma noch die erste Zement-Landepiste beisteuerte. 19301950 fuhr die «Micheline», ein Zug mit Reifen, auf dem Schienennetz in Frankreich und seinen Kolonien. Diese Bahn galt als Flaggschiff der französischen Technologie, die bis heute in der Metro von Paris überlebt hat. Dank immer neuen Innovationen wie der Radialtechnik ab 1946 blieb die Familie weltweit marktführend.

1909 gelang dem deutschen Apotheker Hofmann durch Experimentieren die Synthese von Kautschuk aus Benzin. Die industrielle Fertigung überholte schnell die Produktion aus dem Baumharz aus Süd- 
amerika und dem Kongo, den damals die Belgier ausbeuteten. Anschauliche Modelle demonstrieren die heutige Zusammensetzung eines Autoreifens, der ausser den mehr als 200 weiteren Zutaten wie Kohle, Zink, Schwefel und Stahl immer noch Naturkautschuk enthält. Abrieb, Festigkeit, Treibstoffverbrauch und Rezyklierung sind heute das grosse Thema. Die Fabrik nebenan zeigt auf einer elektronischen Uhr, wie neuentwickelte Profile im Vergleich zu den Konkurrenzmarken weltweit jede Minute den $\mathrm{CO}_{2}$-Ausstoss minimieren. Direkte Konkurrenten sind die Konzerne Bridgestone und Goodyear-Sumitomo. Auch sie produzieren jährlich Millionen Reifen aller Grössen für jeden Anspruch und verbrauchen dafür Tausende Tonnen Stahl und zig Schiffsladungen Öl. Michelin beschäftigt über 100000 Perso- nen, darunter 4000 Forscher. Sie haben 2005 «Tweel» auf den Markt gebracht. Eine Reifenkonstruktion, die ohne Luft auskommt und erstmals für Rollstühle verwendet wird. Leichte Pneus ohne Luft, dafür mit einer Bienenwabenstruktur, sind für Militärs und die Weltraumfahrt interessant. Auf Testgeländen und in Windkammern proben Prototypen von Ambulanzen bis Panzerwagen den Einsatz für alles Erwünschte und Unerwünschte. Zusammen mit den Pionieren des Motorbaus haben die Michelins das 20. Jahrhundert entscheidend mitgeprägt. Sie haben den modernen Sozialstaat vorweggenommen und die Massenmobilität miterfunden. Eine Welt ohne ihre Vehikel sähe völlig anders aus. 